\title{
Design and Performance Analysis of Microstrip Array Antennas with Optimum Parameters for X-band Applications
}

\author{
Md. Tanvir Ishtaique-ul Huque ${ }^{1}$, Md. Kamal Hosain ${ }^{2}$, Md. Shihabul Islam³ ${ }^{3}$ and Md. Al-Amin Chowdhury ${ }^{4}$ \\ Dept. of Electronics and Telecommunication Engineering \\ Rajshahi University of Engineering \& Technology \\ Rajshahi-6204, Bangladesh.
}

\begin{abstract}
This paper demonstrates simple, low cost and high gain microstrip array antennas with suitable feeding techniques and dielectric substrate for applications in $\mathrm{GHz}$ frequency range. The optimum design parameters of the antenna are selected to achieve the compact dimensions as well as the best possible characteristics such as high radiation efficiency, high gain, etc. In this paper different microstrip array antennas such as series feed, corporate feed and corporate- series feed are designed, simulated, analyzed and compared regarding to the antenna performances. The designed antennas are $4 \times 1,4 \times 1$, and $4 \times 2$ arrays. The optimum feeding system is decided based on the various antenna parameters that are simulated. The simulation has been performed by using SONNET version V12.56 simulator which is a commercially available antenna simulator. The designed antennas provide return losses in the range of $-4.21 \mathrm{~dB}$ to $25.456 \mathrm{~dB}$ at frequencies around $10 \mathrm{GHz}$ by using Taconic TLY-5 dielectric substrate with permittivity, $\varepsilon r=2.2$ and height, $h=1.588$ $\mathrm{mm}$. The gain of these simulated antennas is found about $15 \mathrm{~dB}$ and side lobe label is maintained lower than main lobe. Since, the resonance frequency of these antennas is around $10 \mathrm{GHz}$, these antennas are suitable for $X$-band applications such as satellite communication, radar, medical applications, and other wireless systems.
\end{abstract}

Keywords-microstrip antenna; array antenna; corporate-series feed array; corporate feed array; series feed array

\section{INTRODUCTION}

Modern wireless communication system requires low profile, light weight, high gain, and simple structure antennas to assure reliability, mobility, and high efficiency characteristics. Microstrip antenna satisfies such requirements. The key features of a microstrip antenna are relative ease of construction, light weight, low cost and either conformability to the mounting surface or, an extremely thin protrusion from the surface. This antenna provides all of the advantages of printed circuit technology. These advantages of microstrip antennas make them popular in many wireless communication applications such as satellite communication, radar, medical applications, etc[1]. The limitations of microstrip antennas are narrow frequency band and disability to operate at high power levels of waveguide, coaxial line or even stripline. Therefore, the challenge in microstrip antenna design is to increase the bandwidth and gain[2].
Different array configurations of microstrip antenna can give high gain, wide bandwidth and improved efficiency. The distribution of voltages among the elements of an array depends on feeding network. Suitable feeding network accumulates all of the induced voltages to feed into one point [3]. The proper impedance matching throughout the corporate and series feeding array configurations provides high efficiency microstrip antenna[4]. Power distribution among antenna elements can be modified by corporate feed network. The corporate feed network can steer beam by introducing phase change[5].

The choosing of design parameters (dielectric material, height and frequency, etc) is important because antenna performance depends on these parameters. Radiation performance can be improved by using proper design structures [6]. The use of high permittivity substrates can miniaturize microstrip antenna size[7]. Thick substrates with lower range of dielectric offer better efficiency, and wide bandwidth but it requires larger element size[8]. Microstrip antenna with superconducting patch on uniaxial substrate gives high radiation efficiency and gain in millimeter wave lengths [9]. The width discontinuities in a microstrip patch reduces the length of resonating microstrip antenna and radiation efficiency as well [10].

Different radar systems such as synthetic aperture radar (SAR), shuttle imaging radar, remote sensing radars, and other wireless communication systems operate in $\mathrm{L}, \mathrm{C}$ and $\mathrm{X}$ bands. Microstrip antenna is the first option for this high frequency band such as X-band due to its low cost, light weight, and robustness [11]. This article provides a way to choose the design parameters of antennas to achieve the desired dimensions as well as the characteristics for the effective radiation efficiency. This paper also compare the characteristics of series feed, corporate feed and corporate-series feed microstrip array antennas to get optimum feeding system. These designed antennas are potential candidate for the X-band wireless applications due to the simplicity in structure, ease of fabrication and high gain and high efficiency.

\section{MicrostriP ANTENNA DESIGN}

Microstrip patch antennas consist of very thin metallic strip (patch) placed on ground plane where the thickness of the metallic strip is restricted by $\mathrm{t}<<\lambda 0$ and the height is restricted 
by $0.0003 \lambda 0 \leq \mathrm{h} \leq .05 \lambda 0 \quad$ [12-14]. The microstrip patch is designed so that its radiation pattern maximum is normal to the patch. For a rectangular patch, the length $\mathrm{L}$ of the element is usually $\lambda 0 / 3<\mathrm{L}<\lambda 0 / 2$. There are numerous substrates that can be used for the design of microstrip antennas and their dielectric constants are usually in the range of $2.2 \leq \varepsilon \mathrm{r} \leq 12$. To implement the microstrip antennas usually $\mathrm{Fr}-4(\varepsilon \mathrm{r}=4.9)$, Rogers TMM 4( $(\varepsilon r=4.5)$, Taconic TLY-5 $(\varepsilon r=2.2)$, Alumina $(96 \%)(\varepsilon r=9.4)$, Teflon $(\mathrm{PTFE})(\varepsilon r=2.08)$, Arlon AD $5(\varepsilon r=$ 5.1) dielectric materials are used as the substrate[1,12,13].

The Performance of the microstrip antenna depends on its dimension. Depending on the dimension the operating frequency, radiation efficiency, directivity, return loss and other related parameters are also influenced. For an efficient radiation, the practical width of the patch can be written as $[12$, $13,15]$

$$
w=\frac{1}{2 f_{r} \sqrt{\mu_{0} \varepsilon_{0}}} \times \sqrt{\frac{2}{\varepsilon_{r}+1}}
$$

and the length of the antenna becomes

$$
L=\frac{1}{2 f_{r} \sqrt{\varepsilon_{e f f}} \sqrt{\varepsilon_{0} \mu_{0}}}-2 \Delta L
$$

where

and

$$
\Delta L=0.41 h \frac{\varepsilon_{\text {eff }}+0.3}{\varepsilon_{\text {eff }}-0.258} * \frac{\left(\frac{w}{h}+0.264\right)}{\left(\frac{w}{h}+0.8\right)}
$$

$$
\varepsilon_{e f f}=\frac{\varepsilon_{r}+1}{2}+\frac{\varepsilon_{r}-1}{2 \sqrt{1+12 \frac{h}{w}}}
$$

where $\lambda$ is the wave length, fr is the resonant frequency, $\mathrm{L}$ and $\mathrm{W}$ are the length and width of the patch element respectively and $\varepsilon r$ is the dielectric constant. In the following Fig. 1 shows an antenna that has been designed to cover operating frequency of $10 \mathrm{GHz}$ and the quarter wavelength transformer method is used to match the impedance of the patch element with the transmission line $[12,13]$.

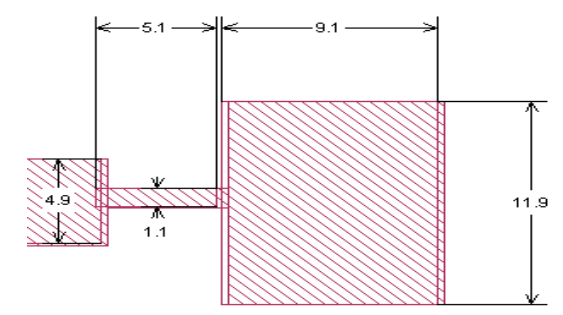

Figure 1. Single element microstrip patch antenna.

\section{PARAMETERS ANAlysis OF Microstrip ANTENNA}

Performance of the microstrip antenna depends on the used dielectric patch material, operating frequency and height of the substrate. As the antenna dimension is bounded by all of these parameters, hence the radiation efficiency as well as the directivity is also influenced. Thus in order to get better performance of a microstrip antenna we need to maintain the value of all of these parameters within a desired threshold level.

Fig. 2 illustrates that the radiation efficiency is near about to independent to relative dielectric constant for $500 \mathrm{MHz}$ operating frequency. Radiation efficiency declines rapidly with dielectric constant for $10 \mathrm{GHz}$ frequency. In summary, with the increasing value of relative dielectric constant, the radiation efficiency of the microstrip antenna is decreased. Thus it needs to choose the dielectric material having a lower dielectric constant near about the air $(\varepsilon r=1)$ to get higher efficiency.

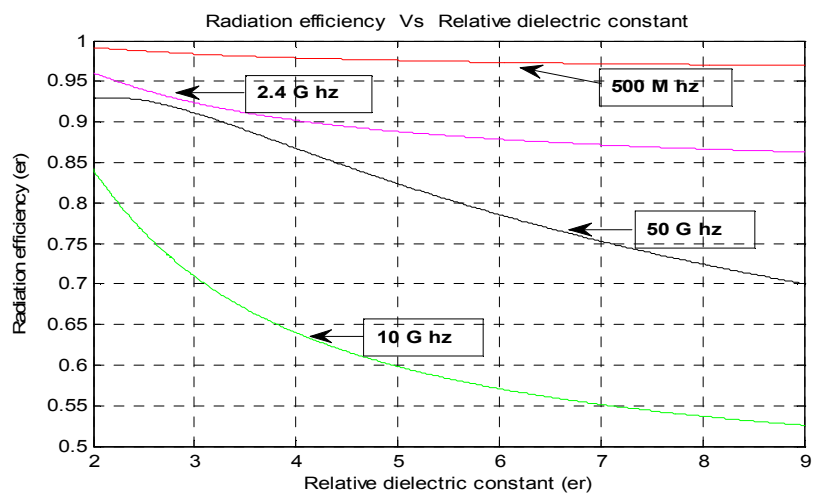

Figure 2. Effect of the dielectric material on the radiation efficiency at different operating frequencies.

Fig. 3 shows that radiation efficiency is the lowest at around $30 \mathrm{GHz}$ operating frequencies. When the operating frequency is below $10 \mathrm{GHz}$ it provides higher radiation efficiency and more higher radiation efficiency can also be achieved by increasing the operating frequency above $50 \mathrm{GHz}$. Teflon (PTFE) is the material which has more efficiency than others.

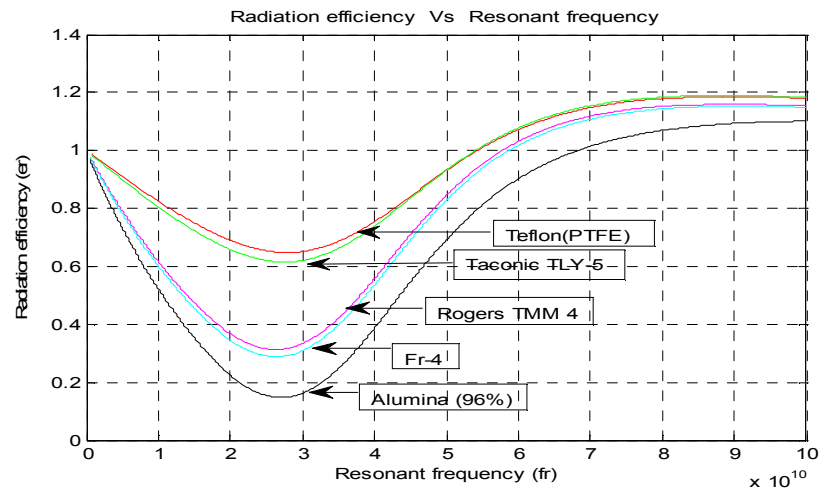

Figure 3. Effect of the operating frequency on the radiation efficiency for different dielectric materials

Fig. 4 describes that radiation efficiency goes down with the increase of the height of substrate. Hence, the lower the value of the height of the substrate as well as its relative dielectric constant, the higher radiation efficiency can be achieved. Fig. 5 demonstrates that at the frequency less than $10 \mathrm{GHz}$, with the growing of the height of the substrate the radiation efficiency is gradually reduces but at the frequency 
greater than $30 \mathrm{GHz}$ it shows the reverse trend where with the increasing of the height of the substrate the radiation efficiency is also increased progressively. For the $500 \mathrm{MHz}$ operating frequency, radiation efficiency is almost independent on the height of the dielectric material.

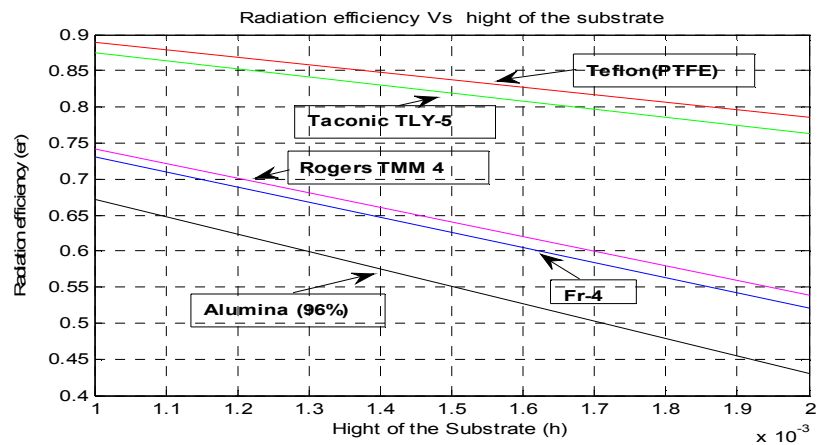

Figure 4. Effect of the radiation efficiency on the height of the dielectric material considering the relative dielectric constant.

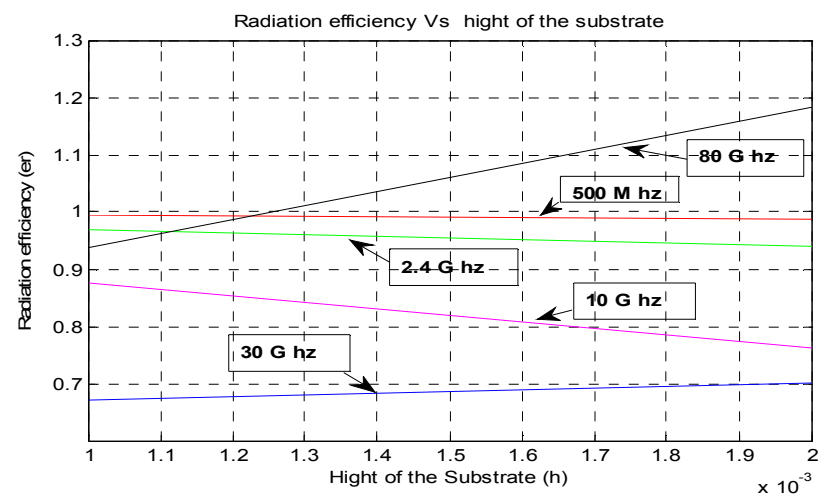

Figure 5. Effect of the radiation efficiency on the height of the dielectric material at different operating frequencies.

Thus after observing the above figures it can be concluded that to get a microstrip antenna having higher radiation efficiency following considerations are required

- The relative dielectric constant of the dielectric material should be less than $3\left(\varepsilon_{\mathrm{r}} \leq 3\right)$ in order to get higher radiation efficiency and directivity.

- The operating (resonant) frequency of the microstrip antenna should be less than $10 \mathrm{GHz}$ or higher than $50 \mathrm{GHz}\left(10 \mathrm{GHz} \geq f_{\mathrm{r}} \geq 50 \mathrm{GHz}\right)$ in order to get improved radiation efficiency. If less than $10 \mathrm{GHz}$ operating frequency range is used, the size of the patch will be increased proportionally and that opposes the fundamental compactness criteria of the microstrip antenna. Therefore it needs to use the operating frequency in the range above $50 \mathrm{GHz}$ to get enhanced efficiency.

- The height (h) of the substrate should be near to $1 \mathrm{~mm}$ to get the higher radiation efficiency. Again, at the higher operating frequency, for the lower height of the substrate, surface wave increases that in turn increases the losses and reduces the radiation efficiency. Thus when the operating frequency is greater than $30 \mathrm{GHz}$ then the radiation efficiency of the microstrip antenna increases with the increasing height of the substrate.

Therefore, for the operating frequency less than $10 \mathrm{GHz}$, the height should be $\mathrm{h} \leq 1.5 \mathrm{~mm}$. For the operating frequency greater than $30 \mathrm{GHz}$, the height should be $\mathrm{h} \geq 1.5 \mathrm{~mm}$.

\section{Microstrip ARRAY ANTENNAS AND FEED NETWORKS}

Microstrip antennas are used not only as single element but also very popular in arrays. Main limitation of microstrip is that it radiate efficiently only over a narrow band of frequencies and they can't operate at the high power levels of waveguide, coaxial line, or even stripline [2]. This can be minimized with the help of various array configurations, feeding methods, dielectric materials and ground planes. Antenna arrays are used to scan the beam of an antenna system, to increase the directivity, gain and enhance various other functions which would be difficult with single element antenna. In the microstrip array, elements can be fed by a single line or multiple lines in a feed network arrangement[12, 13]. Based on their feeding method the arrays are classified as

- $\quad$ Series feed network

- Corporate feed network

- Corporate-series feed network toolbar.

\section{A. Microstrip Series Feed Network}

A series feed microstrip array, as shown in Fig. 6, is formed by interconnecting all the elements with high impedance transmission line and feeding the power at the first element. Here two successive patch elements are matched by using quarter wavelength transformer method. Since, the feed arrangement is compact, the line losses associated with this type of array are lower than those of the corporate feed type [13].

The main beam direction and the scan sensitivity can be calculated from the following equations $[13,16]$

$$
\begin{aligned}
& d \sin \theta+\sqrt{\varepsilon} l=\lambda=\frac{c}{f} \\
& \frac{\partial \theta}{\partial \lambda}=\frac{c}{\partial f^{2} \cos \theta}
\end{aligned}
$$

where $\mathrm{d}$ is the element spacing, 1 is the length of transmission line joining the successive elements, $\mathrm{c}$ is the velocity of light, $\mathrm{f}$ is the operating frequency, and $\theta$ is the beam-pointing angle measured from the broadside direction. For series feed linear array, we consider all excitation amplitude are same. The E-plane radiated fields for a single element patch can be expressed as $[12,17]$

$$
E=j \frac{k_{0} W V_{0} e^{-j k_{0} r}}{r \pi}\left\{\frac{\sin \left(\frac{k_{0} h}{2} \cos \varphi\right)}{\frac{k_{0} h}{2} \cos \varphi}\right\} \cos \left(\frac{k_{0} L_{e}}{2} \sin \varphi\right)
$$

where $\mathrm{W}$ is the width of the patch antenna, $\mathrm{L}_{\mathrm{e}}$ is the extended length, $V_{0}=h E_{0}$ is the voltage across radiating slot of the patch $\mathrm{h}$ 
is the substrate height and $\mathrm{r}$ is the far field distance from the antenna.

The array factor can be written as

$$
F A=\frac{\sin \left(N \pi d_{x}\left(u-u_{0}\right)\right)}{\sin \left(\pi d_{x}\left(u-u_{0}\right)\right)}
$$

where, $\mathrm{u}=\sin \theta, \mathrm{u} 0=\sin \theta 0, \mathrm{dx}$ is the element spacing and $\mathrm{N}$ is the number of elements. Combining array factor and element voltage radiation pattern we get the total element normalized power [18] radiation pattern that is

$$
20 \log (|E / F A|)
$$

The main limitation of the series feed arrays is the large variation of the impedance and beam-pointing direction over a band of frequencies [13].

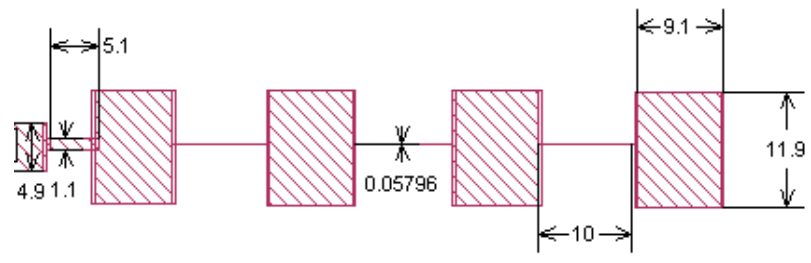

Figure 6. 4-elements series feed microstrip array antenna.

\section{B. Microstrip Corporate Feed Network}

Another popular microstrip antenna feeding system is the corporate feeding. Corporate feed arrays are general and versatile. This method has more control of the feed of each element and is ideal for scanning phased arrays, multi beam arrays. The phase of each element can be controlled using phase shifters while amplitude can be adjusted using either amplifiers or attenuators $[12,18]$. The corporate feed network is used to provide power splits of 2 n (i.e. $n=2 ; 4 ; 8$; 16 ; etc.). This is accomplished by using either tapered lines or using quarter wavelength impedance transformers [13, 17]. Here, in the Fig. 7, the patch elements are connected by using the quarter wavelength impedance transformer method.

The radiated field equation of it is similar to that of the series feed array and the array factor as given in $[18,19]$ as

$$
F A=\frac{\sin ^{2}\left(N \pi\left(d_{x} / \lambda\right) \sin \theta\right)}{N^{2} \sin ^{2}\left(\pi\left(d_{x} / \lambda\right) \sin \theta\right)}
$$

We can get the normalized power radiation pattern by combining the element radiation pattern and array factor [20].

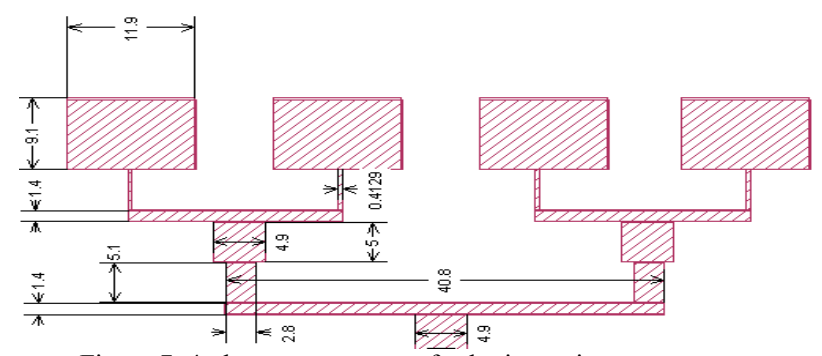

Figure 7. 4-elements corporate feed microstrip array antenna.

\section{Microstrip Corporate-Series Feed Network}

The combination of series feed and corporate feed are frequently used for array antennas $[16,19]$ to get benefits of both feeding networks. An 8-elemants array antenna can be constructed by using this method as shown in Fig. 8. It is a two dimensional rectangular planar array whose aperture illumination can be separated into two orthogonal planes such as the horizontal and vertical planes and the radiation pattern may then be written as the product the radiation patterns in these two planes. The array factor of this antenna with element spacing in the $\mathrm{x}$ and $\mathrm{y}$ direction of $\mathrm{dx}$ and dy respectively as given in [18] is

$$
F A=\frac{\sin ^{2}\left(N \pi\left(d_{x} / \lambda\right) \sin \theta_{a}\right) \times \sin ^{2}\left(M \pi\left(d_{y} / \lambda\right) \sin \theta_{a}\right)}{\left(N^{2} \sin ^{2}\left(\pi\left(d_{x} / \lambda\right) \sin \theta_{a}\right)\right) \times\left(M^{2} \sin ^{2}\left(\pi\left(d_{y} / \lambda\right) \sin \theta_{a}\right)\right)}
$$

where $\mathrm{N}=$ number of vertical elements of array that gives rise to the azimuth angle, $\theta \mathrm{a}$ and $\mathrm{M}=$ number of horizontal elements of array that gives rise to the elevation angle, $\theta \mathrm{e}$. Multiplying the above equation with element radiated field gives normalized power radiation pattern.

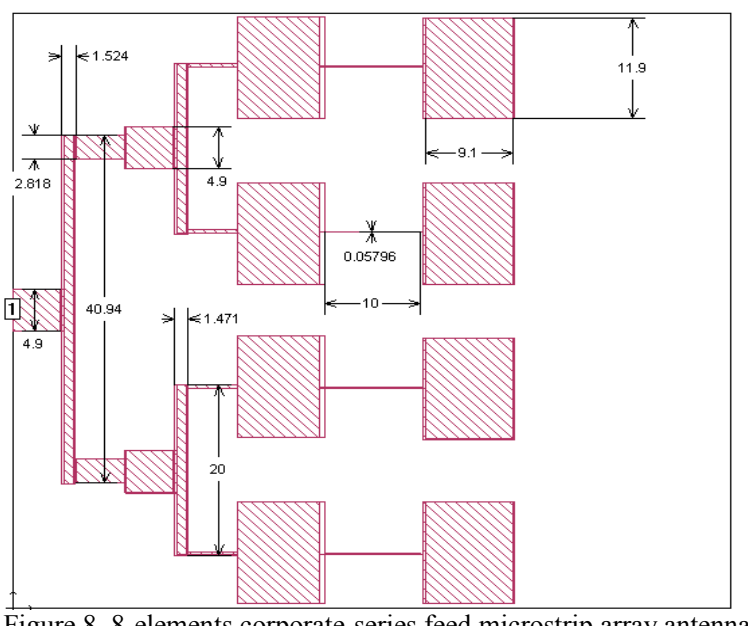

\section{Simulation Result \& Discussion}

\section{A. Series Feed Array}

In this design, it is considered that the substrate permittivity of the antenna is 2.2 (Taconic TLY-5), height is $1.588 \mathrm{~mm}$, and resonance frequency of the antenna is $10 \mathrm{GHz}$. Fig. 9 illustrates the current distribution of 4-elements series feed microstrip array antenna. It is apparent that current distribution is near about the same in each element. Fig. 10 shows that the return loss is $-4.21 \mathrm{~dB}$ at $10 \mathrm{GHz}$ and it is maximum of $-6.26 \mathrm{~dB}$ at $10.9 \mathrm{GHz}$. Since the return loss is higher in lower frequency band, therefore antenna efficiency is lower at these frequencies. The maximum antenna efficiency can be obtained at $10.9 \mathrm{GHz}$ frequency. The simulated gain and directive gain of the antenna, according to fig. 11 , are $11.97 \mathrm{~dB}$ and $27.21 \mathrm{~dB}$ respectively at $\theta=-25^{0}, \varphi=0^{0}$ for the operating frequency $10 \mathrm{GHz}$. 


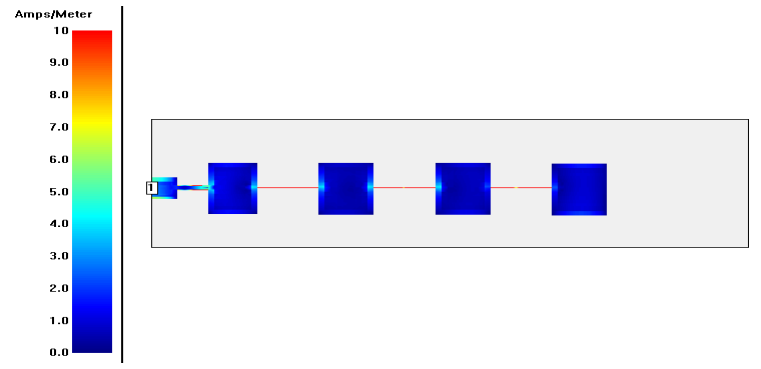

Figure 9. Current distribution of the 4-elements series feed microstrip array antenna.

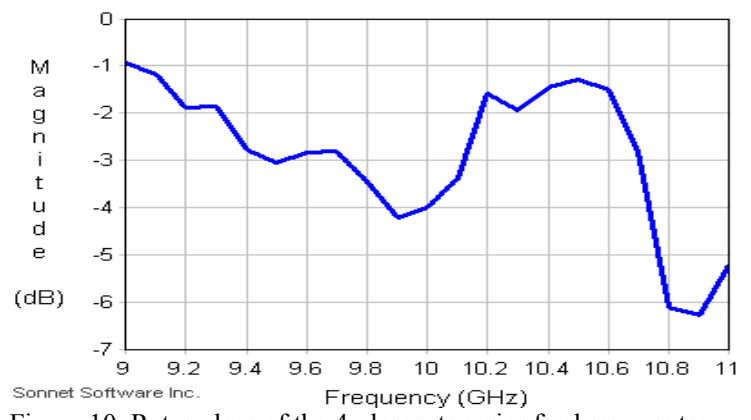

Figure 10. Return loss of the 4-elements series feed array antenna.

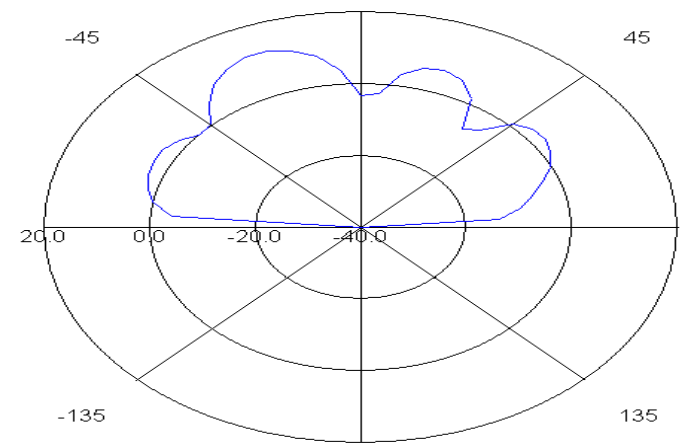

Figure 11. Radiation (polar plot) pattern of the 4-elements series feed array antenna.

\section{B. Corporate Feed Array}

Fig. 12 describes the current distribution of 4-elements corporate feed microstrip array antenna. In this array network, two successive patch elements as well as their corresponding transmission lines are matched by using quarter wavelength transformer method. Here, the substrate permittivity of the antenna is 2.2 (Taconic TLY-5), height is $1.588 \mathrm{~mm}$ and resonance frequency of the antenna is $10 \mathrm{GHz}$. Fig. 13 presents that the maximum return loss is $-25.456 \mathrm{~dB}$ at $10 \mathrm{GHz}$. Return losses increases for both lower and higher frequencies. Fig. 14 shows that the simulated gain and directive gain of the antenna are $14.14 \mathrm{~dB}$ and $19.245 \mathrm{~dB}$ respectively at $\theta=00, \varphi=00$ for the operating frequency $10 \mathrm{GHz}$.

\section{Corporate-Series Feed Array}

Fig. 15 illustrates the current distribution of 8-elements corporate-series feed microstrip array antenna. It is clear from the figure that the amount of current declines at the edge of elements. The same substrate as in series feed antenna of Taconic TLY-5 is used. The resonance frequency of the designed antenna is $10 \mathrm{GHz}$. Fig. 16 demonstrates that return loss is $-7.55 \mathrm{~dB}$ at $10 \mathrm{GHz}$ and the peak value of return loss is -
$17.96 \mathrm{~dB}$ at $9.6 \mathrm{GHz}$. The simulated gain and directive gain of the antenna, as shown in fig. 17 are $17.48 \mathrm{~dB}$ and $20.001 \mathrm{~dB}$ respectively at $\theta=00, \varphi=00$ for the operating frequency of $10 \mathrm{GHz}$.
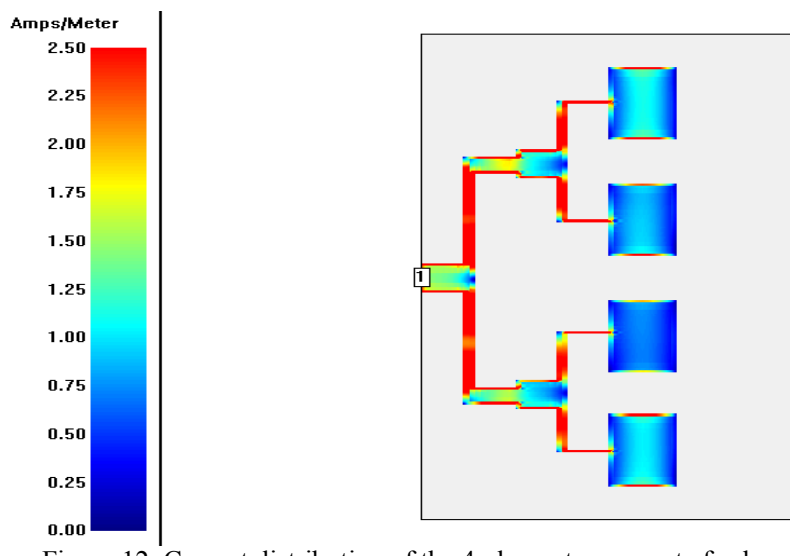

Figure 12. Current distribution of the 4-elements corporate feed microstrip array antenna.

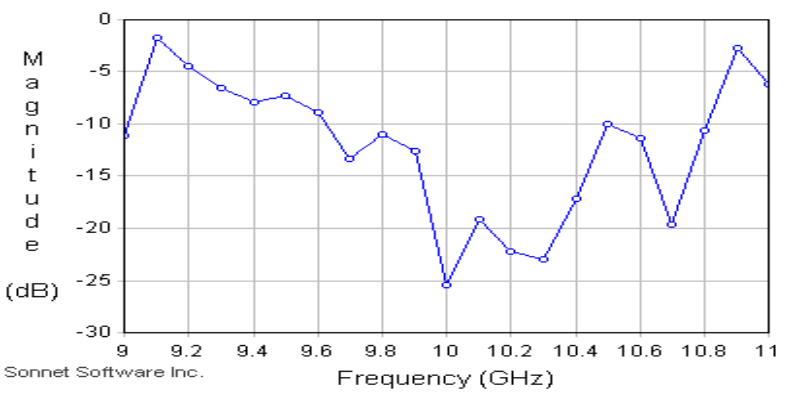

Figure 13. Return loss of the 4-elements corporate feed array antenna.

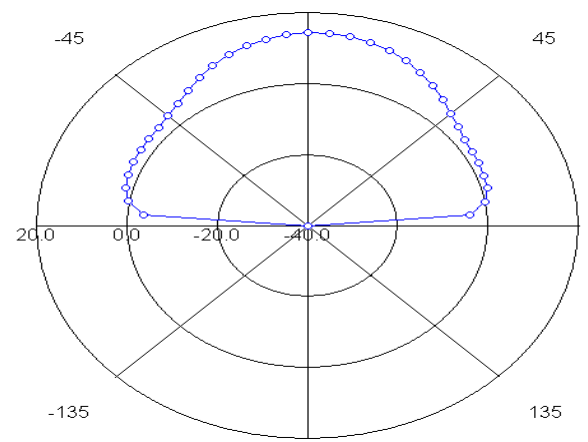

Figure 14. Radiation (polar plot) pattern of the 4-elements corporate feed array antenna.

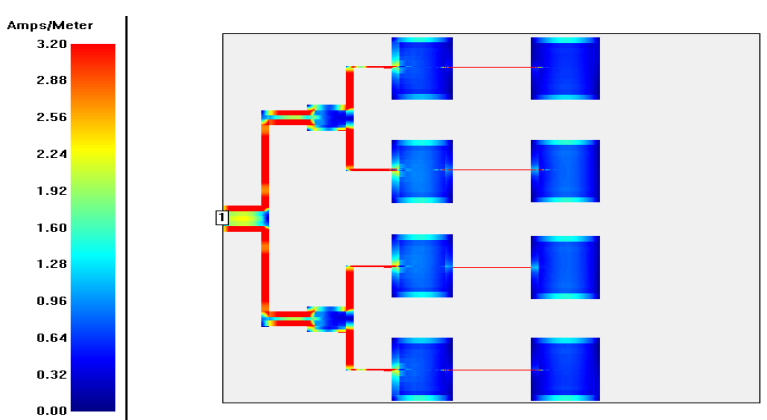

Figure 15. Current distribution of the 8-elements corporate-series feed microstrip array antenna. 


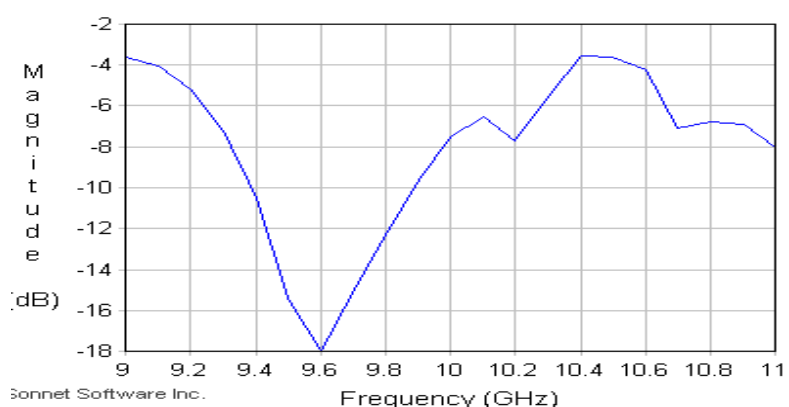

Figure 16. Return loss of for the 8-elements corporate-series feed array.

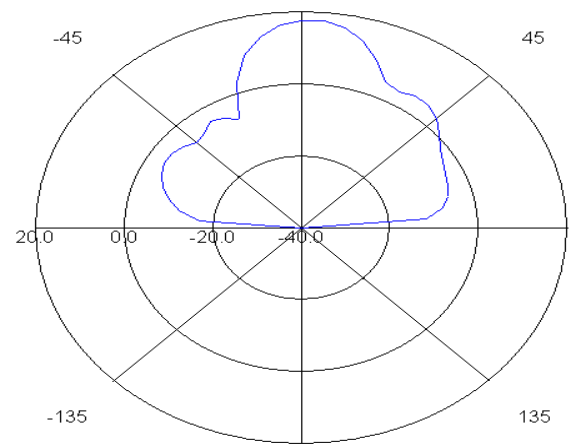

Figure 17. Radiation (polar plot) pattern of the 8-elements corporateseries feed array antenna

\section{Comparison Among Three Differently Feed antennas}

Table 1 compares three types of feed antennas. Series feed array is a simple and compact feeding method. As the feed arrangement is compact, the line losses associated with this type of array are lower than those of the corporate feed type. But this feeding gives a poor directive gain $(\mathrm{HPBW}=140.30)$ with a large variation of beam-pointing directions. The corporate feed array has more control of the feed of each element as shown in fig. 12 whereas the current density of all elements are same near about $1 \mathrm{amp} /$ meter. The peak value of return loss for corporate feeding is $-25.456 \mathrm{~dB}$ that is very much lower than that of series feed array of $-4.21 \mathrm{~dB}$. As a result corporate feeding antennas have higher radiation efficiency than series feed antennas. In addition, corporate feeding provides better directivity and reduces the beam fluctuations over a band of frequencies.

The corporate-series feed array is a combination of these two feeding methods. This combined feeding offers HPBW of $400-600$ and simulated gain of $17.48 \mathrm{~dB}$ that are highest among three feeding methods. Therefore, it presents not only better directivity performance as the corporate feed array but also achieve a reduction of transmission line associated loss as the series feed array which can be easily realized by observing and comparing the current distribution of the fig. 9, fig. 12 and fig. 15 for series feed, corporate feed and corporate-series feed array antennas respectively.
TABLE I. COMPARISON AMONG ThreE DifFERENTLy FeED ANTENNAS

\begin{tabular}{|c|c|c|c|}
\hline \multirow{2}{*}{$\begin{array}{c}\text { Performance } \\
\text { Parameter }\end{array}$} & $\begin{array}{c}\text { Series feed } \\
\mathbf{( 4 x 1 ) a r r a y}\end{array}$ & $\begin{array}{c}\text { Corporate feed } \\
\mathbf{( 4 x 1 ) a r r a y}\end{array}$ & $\begin{array}{c}\text { Corporate- } \\
\text { series } \\
\mathbf{( 4 x 2 ) f e e d ~} \\
\text { array }\end{array}$ \\
\hline $\begin{array}{c}\text { Physical } \\
\text { Dimension }\end{array}$ & One & One & Two \\
\hline HPBW & About $140.3^{0}$ & About $95.6^{0}$ & $40^{0}-60^{0}$ \\
\hline $\begin{array}{c}\text { Simulated } \\
\text { gain(dB) }\end{array}$ & 11.97 & 14.14 & 17.48 \\
\hline $\begin{array}{c}\text { Transmission } \\
\text { line loss }\end{array}$ & Higher & Lower & Moderate \\
\hline Return loss(dB) & -4.21 & -25.456 & -7.55 \\
\hline
\end{tabular}

\section{CONCLUSION}

These designed antennas are very simple, cost effective and high efficiency for the applications in $\mathrm{GHz}$ frequency ranges. The optimum design parameters (i.e. dielectric material, height of the substrate, operating frequency) are used to achieve the compact dimensions and high radiation efficiency. On the other hand, corporate-series feed antenna merges the advantages of both series and corporate feed antennas. The combined feeding antenna is planar array, therefore, this antenna can control the beam shape in both planes and provides more directivity and radiation efficiency. The operating frequency of all our designed antennas is about $10 \mathrm{GHz}$ which is suitable for X-band applications. It would also be possible to design an antenna operating in any other frequency bands by changing the design parameters. In future, we will investigate the spiral arrays with different feeding techniques which seem to be having more improved performances for both the series feed and corporate feed networks. At the same time, we will merge more than two patch elements operating at different frequencies by using quarter wavelength transformer method within an array network configuration to get multiband support.

\section{REFERENCES}

[1] M. T. I. Huque, et al., "Design and Simulation of a Low-cost and High Gain Microstrip Patch Antenna Arrays for the X-band Applications," in International Conference on Network Communication and Computer ICNCC 2011, New Delhi, India., March 21-23, 2011.

[2] R. Mailloux, et al., "Microstrip array technology," Antennas and Propagation, IEEE Transactions on, vol. 29, pp. 25-37, 1981.

[3] H. Cheng-Chi, et al., "An aperture-coupled linear microstrip leaky-wave antenna array with two-dimensional dual-beam scanning capability," Antennas and Propagation, IEEE Transactions on, vol. 48, pp. 909-913, 2000.

[4] K. Gi-Cho, et al., "Ku-band high efficiency antenna with corporateseries-fed microstrip array," in Antennas and Propagation Society International Symposium, 2003. IEEE, 2003, pp. 690-693 vol.4.

[5] A. Abbaspour-Tamijani and K. Sarabandi, "An affordable millimeterwave beam-steerable antenna using interleaved planar subarrays," Antennas and Propagation, IEEE Transactions on, vol. 51, pp. 21932202, 2003.

[6] A. Boufrioua and A. Benghalia, "Effects of the resistive patch and the uniaxial anisotropic substrate on the resonant frequency and the scattering radar cross section of a rectangular microstrip antenna," Aerospace science and technology, vol. 10, pp. 217-221, 2006. 
[7] K. C. Lo and Y. Hwang, "Microstrip antennas of very high permittivity for personal communications," 1997, pp. 253-256 vol.

[8] J. M. Rathod, "Design Development of Antenna for TV Transmission for Connecting Outdoor Broadcasts Van to the Studio for Rural Areas," International Journal of Computer and Electrical Engineering, vol. 2, pp. 251-256, 2010.

[9] O. Barkat and A. Benghalia, "Radiation and resonant frequency of superconducting annular ring microstrip antenna on uniaxial anisotropic media," Journal of Infrared, Millimeter and Terahertz Waves, vol. 30, pp. 1053-1066, 2009.

[10] L. Choon Sae and T. Kuo-Hua, "Radiation efficiency of electrically small microstrip antennas with width discontinuities," Antennas and Propagation, IEEE Transactions on, vol. 53, pp. 871-873, 2005.

[11] M. F. Islam, et al., "Dual band microstrip patch antenna for SAR applications," Australian Journal of Basic and Applied Sciences, vol. 4, pp. 4585-4591, 2010.

[12] C. A. Balanis. (2005). Antenna theory : analysis and design (3rd ed.).

[13] R. Garg, Microstrip antenna design handbook. Boston, Mass. [u.a.]: Artech House, 2001.

[14] M. T. I. u. Huque, et al., "Design and performance analysis of the rectangular spiral microstrip antenna and its array configuration," in Antennas Propagation and EM Theory (ISAPE), 2010 9th International Symposium on, 2010, pp. 219-221.

[15] T. A. Milligan, et al. (2005). Modern antenna design. Available: http://dx.doi.org/10.1002/0471720615

[16] M. M. Alam, et al., "Design and performance analysis of microstrip array antenna," Session 5AP, p. 846.

[17] R. J. Mailloux, "Electronically Scanned Arrays," Synthesis Lectures on Antennas, vol. 2, pp. 1-82, 2007.

[18] H. J. Visser, "Array and Phased Array Antenna Basics," ed: John Wiley \& Sons.

[19] M. I. Skolnik, Introduction to radar systems, 3rd ed. New York,: McGraw-Hill, 2000.
[20] W. L. Stutzman, "Estimating directivity and gain of antennas," Antennas and Propagation Magazine, IEEE, vol. 40, pp. 7-11, 1998.

\section{AUTHORS PROFILE}

Md. Tanvir Ishtaique-ul Huque was born in 1988 in Bangladesh. He received his B.Sc. Engineering degree from the Rajshahi University of Engineering \& Technology (RUET) in 2010. Now he is working as a part time teacher in the Dept. of Electronics and Telecommunication Engineering of RUET. His research interests include the antenna application of the wireless body area network(WBAN) and next generation wireless communication system.

Md. Kamal Hosain was born in 1984 in Bangladesh. He received his B.Sc. Engineering degree from the Khulna University of Engineering \& Technology (KUET), Bangladesh in 2006. Now, he is working as a Lecturer in the Dept. of Electronics and Telecommunication Engineering (ETE) of RUET. His research interests include the antennas and its medical applications.

Md. Shihabul Islam was born in 1987 in Bangladesh. He received his B.Sc. Engineering degree from the Rajshahi University of Engineering \& Technology(RUET) in 2010 and now he is working as a system engineer of Technology Division in Grameen Phone Ltd. Which is a part of Telenor Group. His research interests include the antenna application and wireless sensor network.

Md. Al-Amin Chowdhury was born in 1988 in Bangladesh. he has completed his B.Sc. in Electronic and Telecommunication Engineering from Rajshahi University of Engineering \& Technology(RUET) in 2010. He has keen interest to research on the optical fiber, different types of antennas. He wants to do his further study in USA on the communication field. World is becoming closer and closer due to the remarkable achievements in the communication field. He wants to receive the sound and proper knowledge in communication field so that he can contribute to the next generation demands in the communication sectors. 